\title{
A Facile Low-Temperature Hydrothermal Method to Prepare Anatase Titania/Cellulose Aerogels with Strong Photocatalytic Activities for Rhodamine B and Methyl Orange Degradations
}

\author{
Caichao Wan, ${ }^{1}$ Yun Lu, ${ }^{2}$ Chunde Jin, ${ }^{3}$ Qingfeng Sun, ${ }^{3}$ and Jian Li ${ }^{1}$ \\ ${ }^{1}$ Material Science and Engineering College, Northeast Forestry University, Harbin 150040, China \\ ${ }^{2}$ Research Institute of Wood Industry, Chinese Academy of Forestry, Beijing 100091, China \\ ${ }^{3}$ School of Engineering, Zhejiang Agricultural and Forestry University, Lin'an 311300, China \\ Correspondence should be addressed to Yun Lu; luyun@criwi.org.cn, Qingfeng Sun; qfsun@nefu.edu.cn and \\ Jian Li; nefulijian@163.com
}

Received 12 August 2014; Revised 8 October 2014; Accepted 8 October 2014

Academic Editor: Chuanfei Guo

Copyright (C) 2015 Caichao Wan et al. This is an open access article distributed under the Creative Commons Attribution License, which permits unrestricted use, distribution, and reproduction in any medium, provided the original work is properly cited.

A facile low-temperature hydrothermal method for in situ preparation of anatase titania $\left(\mathrm{TiO}_{2}\right)$ homogeneously dispersed in cellulose aerogels substrates was described. The formed anatase $\mathrm{TiO}_{2}$ aggregations composed of a mass of evenly dispersed $\mathrm{TiO}_{2}$ nanoparticles with sizes of $2-5 \mathrm{~nm}$ were embedded in the interconnected three-dimensional (3D) architecture of the cellulose aerogels matrixes without large-scale reunion phenomenon; meanwhile, the obtained anatase titania/cellulose (ATC) aerogels also had a high loading amount of $\mathrm{TiO}_{2}$ (ca. 35.7\%). Furthermore, compared with commercially available Degussa P25, ATC aerogels displayed comparable photocatalytic activities for Rhodamine B and methyl orange degradations under UV radiation, which might be useful in the fields of catalysts, wastewater treatment, and organic pollutant degradation. Meanwhile, the photocatalytic reaction behaviors of ATC aerogels under UV irradiation were also illuminated.

\section{Introduction}

Titanium dioxide $\left(\mathrm{TiO}_{2}\right)$, one of the most important semiconductor materials, has been extensively applied as photocatalyst for decontamination of water polluted with organic pollutants due to its high optical reactivity, chemical and physical inertness, nontoxicity, and low cost [1-3]. $\mathrm{TiO}_{2}$ crystals mainly exist in two stable polymorphic forms: anatase (tetragonal, space group $I 4_{1} /$ amd) and rutile (tetragonal, space group $\mathrm{P}_{2} / \mathrm{mnm}$ ) [4]. Generally, it is accepted that anatase $\mathrm{TiO}_{2}$ is more efficient as photocatalyst, and rutile $\mathrm{TiO}_{2}$ is preferable for blocking UV irradiation, notwithstanding that some catalysts with mixed phases exhibit significantly higher catalytic activities like Degussa P25 [5, 6].

In fact, nanoscale particles with large specific surface area and high surface energy are very easy to reunite leading to conspicuous performance degradation. The confinement of nanoparticles can be achieved by using some special matrixes with unique structures as hosts like multiwalled carbon nanotubes [7-9], graphene [10], fibers [11], and some traditional inorganic or synthetic polymer-based aerogels $[12,13]$, which could provide a means of particle dispersion and act as protection of metallic nanoparticles against air oxidation. In particular, owing to large specific surface area, high porosity, multiscale micronanostructure, stable chemical property, renewability, and biodegradability, cellulose aerogels are widely considered as good supports for nanomaterials, such as $\mathrm{TiO}_{2}, \mathrm{ZnO}, \mathrm{Ag}$, and $\mathrm{ZrO}_{2}[14-$ 17]. In particular, $\mathrm{TiO}_{2}$ /cellulose aerogels hybrids are useful for photocatalysts, UV shields, antibacterial materials, and synthesis of transition-metal carbide materials [18-21]. Furthermore, synthesis of anatase $\mathrm{TiO}_{2}$ /cellulose (ATC) composites generally depends on high-temperature calcination treatment using cellulose or cellulose derivatives as templates at $400-700^{\circ} \mathrm{C}[22-24]$, so as to get anatase $\mathrm{TiO}_{2}$ crystals and 
avoid excessive crystal transformation from anatase to rutile while exceeding the critical temperature.

Herein, a facile low-temperature hydrothermal method was employed to prepare ATC aerogels instead of the common calcination process. Moreover, distinguishing from some previous literatures about $\mathrm{TiO}_{2}$ /cellulose composites with improved activity, in this study, a green $\mathrm{NaOH} /$ polyethylene glycol (PEG) aqueous solution was used to fabricate the cellulose aerogels, and the resulting environmentally friendly nanoporous aerogels were selected as hosts to support the nano- $\mathrm{TiO}_{2}$. The obtained ATC aerogels were characterized by scanning electron microscopy (SEM), transmission electron microscopy (TEM), energy dispersive Xray spectroscopy (EDX), X-ray photoelectron spectroscopy (XPS), X-ray diffraction (XRD), and thermogravimetry (TG). Meanwhile, the photocatalytic activities of ATC aerogels for two typical organic pollutants including Rhodamine $\mathrm{B}(\mathrm{RhB})$ and methyl orange (MO) degradations were also investigated and compared with those of P25. Based on which, the photocatalytic reaction behaviors of ATC aerogels under UV irradiation were illuminated.

\section{Materials and methods}

2.1. Materials. Sixty-mesh powder of wheat straw after grinding and sieving was collected and dried in a vacuum at $60^{\circ} \mathrm{C}$ for $24 \mathrm{~h}$ before being used. All chemicals were supplied by Tianjin Kemiou Chemical Reagent Co., Ltd., and used as received.

2.2. Cellulose Hydrogel Preparation. A mild effective chemical pretreatment process was employed to extract and purify cellulose from the wheat straw powder, which could refer to our previous report [25]. The obtained dried cellulose was mixed with an aqueous solution of NaOH/PEG-4000 (9:1 by weight) with magnetic stirring at room temperature for about $6 \mathrm{~h}$ to form a $2 \mathrm{wt} \%$ homogenous cellulose solution. Then, the cellulose solution underwent a freeze-thaw process by freezing the solution at $-15^{\circ} \mathrm{C}$ for $12 \mathrm{~h}$ and subsequently thawing it out at room temperature for $0.5 \mathrm{~h}$ under vigorous stirring. After being frozen again for $3 \mathrm{~h}$ at $-15^{\circ} \mathrm{C}$, the solution was regenerated by placing it into a coagulation bath of $1 \mathrm{v} \%$ hydrochloric acid for $6 \mathrm{~h}$, repeating this process until the formation of the amber-like hydrogel. Afterwards, the obtained hydrogel was rinsed repeatedly with distilled water and anhydrous ethyl alcohol (EtOH) to remove superfluous hydrogen ions and chlorine anions.

2.3. ATC Aerogel Preparation. The low-temperature hydrothermal preparation of ATC aerogel was described in Scheme 1. Tetrabutyl orthotita (TBOT) $(5 \mathrm{~mL})$ and $\mathrm{EtOH}$ $(200 \mathrm{~mL})$ were mixed with magnetic stirring for $30 \mathrm{~min}$ and then transferred into a Teflon-lined stainless-steel autoclave. The cellulose hydrogel was subsequently placed into the above reaction solution. After the autoclave was sealed and heated to $110^{\circ} \mathrm{C}$ for $4 \mathrm{~h}, 100 \mathrm{~mL}$ deionized water $(\mathrm{pH}=6.5)$ was added, and the solution was reheated to $70^{\circ} \mathrm{C}$ for $4 \mathrm{~h}$. After reaction, the prepared sample was removed from the solution and ultrasonically rinsed with deionized water and tert-butyl alcohol in sequence for $30 \mathrm{~min}$. Finally, the sample was subjected to a freeze-drying process at $-35^{\circ} \mathrm{C}$ for $48 \mathrm{~h}$, and the following ATC aerogel was successfully fabricated. Moreover, the pure $\mathrm{TiO}_{2}$ particles powders were prepared following the above hydrothermal process without adding the cellulose hydrogel, and the mixed solution after reaction was filtered, washed by distilled water, and dried at $60^{\circ} \mathrm{C}$ for $24 \mathrm{~h}$ to get dried $\mathrm{TiO}_{2}$ particles powders. The pure cellulose aerogel was obtained by the direct tert-butyl alcohol freezedrying process of the cellulose hydrogel.

2.4. Characterizations. Microstructures and surface chemical compositions were evaluated by SEM (FEI, Quanta 200) equipped with EDX spectrometer operating at $15-20 \mathrm{kV}$ on gold-sputtered samples. TEM observation was carried out on a FEI, Tecnai G2 F20 TEM. Crystalline structures were identified by XRD instrument (Rigaku, D/MAX 2200) operating with $\mathrm{Cu} \mathrm{K} \alpha$ radiation $(\lambda=1.5418 \AA \hat{\mathrm{A}})$ at a scan rate $(2 \theta)$ of $4^{\circ} \cdot \mathrm{min}^{-1}$, accelerating voltage of $40 \mathrm{kV}$, and applied current of $30 \mathrm{~mA}$ ranging from $10^{\circ}$ to $80^{\circ}$. XPS spectra were recorded using a Thermo Escalab 250Xi XPS spectrometer (Germany). Deconvolution of the overlapping peaks was performed using a mixed Gaussian-Lorentzian fit program. Thermal stabilities were determined using a TG analyzer (TA Q600) with a heating rate of $10^{\circ} \mathrm{C} \cdot \mathrm{min}^{-1}$ in a $\mathrm{N}_{2}$ environment.

2.5. Photocatalytic Activities Measurements. The photocatalytic activities of ATC aerogels were evaluated by measuring the decomposition of $\mathrm{RhB}$ and $\mathrm{MO}$, while pure $\mathrm{TiO}_{2}$ nanoparticles (commercial Degussa P25) were used for comparison, and the amount of P25 and the amount of ATC aerogels were controlled by the same titania loading determined by the following TG tests. A $100 \mathrm{~W}$ mercury lamp with main wavelength of $365 \mathrm{~nm}$ was purchased from Beijing BrightStars Science and Technology Corp. and selected as UV light source. For typical photocatalytic experiments of the hybrid aerogels, ATC aerogels samples with sizes of about $20 \mathrm{~mm}$ (diameter) $\times 10 \mathrm{~mm}$ (height) were immersed into the circular disks with $30 \mathrm{~mL} \mathrm{RhB}$ or $\mathrm{MO}$ aqueous solutions $\left(50 \mathrm{mg} \cdot \mathrm{L}^{-1}\right)$, respectively. Before irradiation, the solutions with ATC aerogels were magnetically stirred in the dark for $30 \mathrm{~min}$ to achieve adsorption equilibrium. Then, the dishes were exposed to the mercury lamp for about $1 \mathrm{~h}$, and the distances between the lamps and the dishes were approximately $10 \mathrm{~cm}$. Samples were taken at every time interval $(20 \mathrm{~min})$ and centrifuged for removing photocatalysts. Concentration of the filtrate was analyzed by a TU-1901 UVvis spectrophotometer (Beijing Purkinje, China) at $554 \mathrm{~nm}$ for $\mathrm{RhB}$ or $464 \mathrm{~nm}$ for MO. The efficiency was calculated by

$$
Y=100 \times\left(\frac{C-C_{0}}{C_{0}}\right),
$$

where $C_{0}$ and $C$ are the initial dye concentration and the concentration at time $t$, respectively. Similarly, the photocatalytic experiments of $\mathrm{P} 25$ for $\mathrm{RhB}$ and $\mathrm{MO}$ were following the above procedures. 


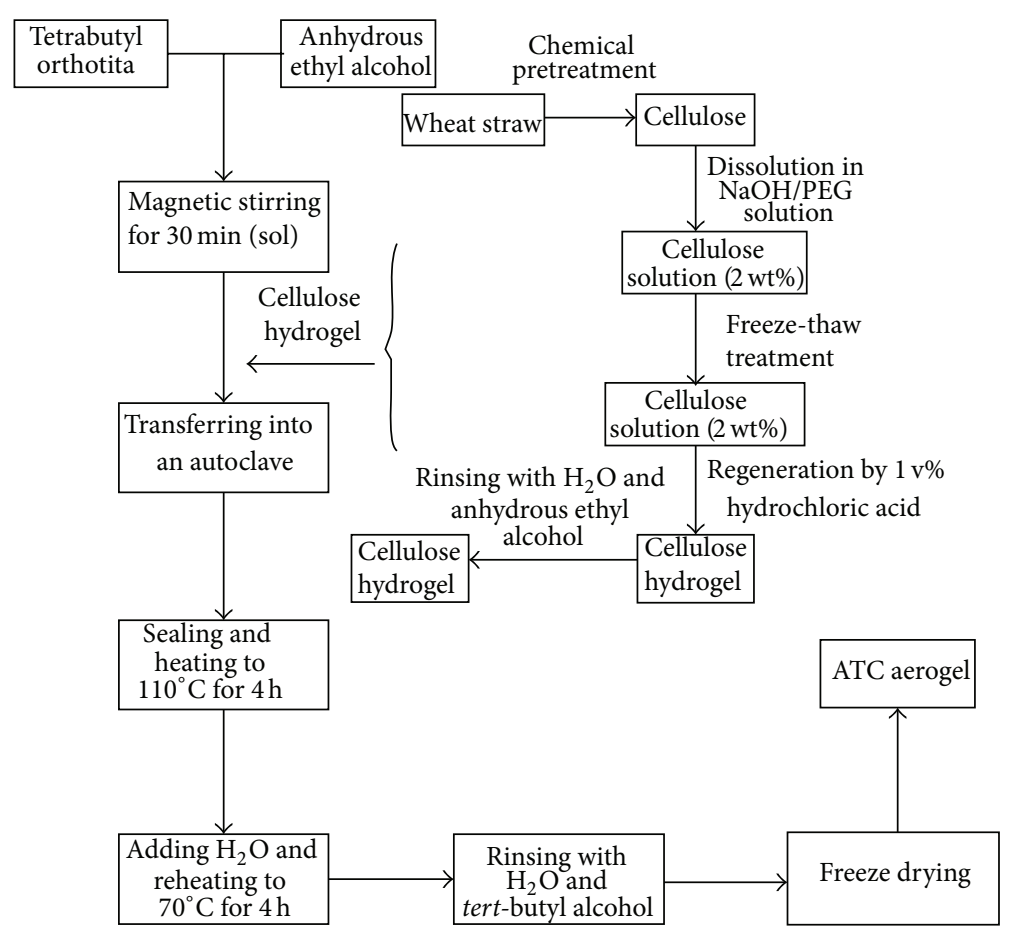

Scheme 1: Diagram of the low-temperature hydrothermal preparation of ATC aerogel.

\section{Results and Discussion}

Figure 1(a) showed the SEM image of ATC aerogels. As shown, porous and interconnected three-dimensional (3D) architecture with pore sizes of a few hundred nanometers to several micrometers, originated from the original cellulose hydrogels architecture, could be clearly identified. In addition, it was observed that numerous white ellipsoidal substances surrounding the porous skeleton structure were generated, which might be derived from titanium compounds. To further investigate the chemical components of the newly generated white ellipsoidal substances, the area in the green box with some evident aggregations of particles (Figure 1(a)) was tested by EDX, and the results demonstrated that apart from $\mathrm{C}$ and $\mathrm{O}$ elements from the cellulose substrates as well as $\mathrm{Au}$ element from the coating layer used for SEM observation, new strong peaks corresponding to Ti element were detected (inset in Figure 1(a)), confirming that the white ellipsoidal substances primarily consisted of titanium compounds. Moreover, from the higher magnification SEM image (Figure 1(b)), it was clear that the ellipsoidal substances containing Ti element tightly adhered to the cellulose matrixes, indicating potential good interface bonding.

In order to further explore the composition and structure of the ellipsoidal substances as well as the interaction between the ellipsoidal substances and the cellulose aerogels matrixes, the samples were observed by TEM. The TEM images of different magnifications of ATC aerogels were represented in Figure 2. Apparently, the cellulose aerogels matrixes were loaded with a mass of evenly dispersed nanoparticles as indicated by the dark spots in the TEM image with lower magnification (Figure 2(a)). These abundant particles might be responsible for the formation of the ellipsoidal substances. The higher magnification TEM image (Figure 2(b)) showed that the size of nanoparticles was found to range between 2 and $5 \mathrm{~nm}$ and no large-scale aggregation was observed, indicating that the combination of nanoparticles and cellulose aerogels effectively hindered the reunion phenomenon.

XPS measurements were performed to elucidate the surface chemical composition and the oxidation state of ATC aerogels. In the high-resolution XPS spectra of Ti $2 p$ (Figure $3(\mathrm{a})$ ), the binding energies of Ti $2 \mathrm{p}_{3 / 2}$ and $2 \mathrm{p}_{1 / 2}$ were centered at 457.2 and $462.5 \mathrm{eV}$, respectively, which revealed that the titanium elements were in the oxidation state IV, corresponding to $\mathrm{Ti}^{4+}\left(\mathrm{TiO}_{2}\right)[26,27]$. Meanwhile, the result also suggested that the ellipsoidal substances observed by SEM were composed of $\mathrm{TiO}_{2}$ particles; besides, the nanoparticles in the TEM images might be exactly the generated $\mathrm{TiO}_{2}$ particles. The $\mathrm{O}$ 1s spectra of ATC aerogels displayed the contributions of three components (Figure 3(b)) including $\mathrm{TiO}_{2}(529.8 \mathrm{eV})$, adsorbed water $(531.2 \mathrm{eV})$, and hydroxyl groups $(\mathrm{O}-\mathrm{H})(532.1 \mathrm{eV})$ [28]. Moreover, in the $\mathrm{C}$ 1s spectra (Figure 3(c)), major peak at $284.7 \mathrm{eV}$ was related to $\mathrm{C}-\mathrm{C}$, $\mathrm{C}=\mathrm{C}$, and $\mathrm{C}-\mathrm{H}$ bonds and the peak at around $287.7 \mathrm{eV}$ suggested the presence of $\mathrm{Ti}-\mathrm{O}-\mathrm{C}$ bond [29].

The XRD patterns of the $\mathrm{TiO}_{2}$ particles and ATC aerogels were shown in Figure 3(d). For the $\mathrm{TiO}_{2}$ particles, a series of characteristic peaks, corresponding to the (103), (004), (112), (200), (105), (211), (213), (204), (116), (220), (107), (215), and (301) planes, were observed, which were regarded as an attributive indicator of anatase phase $\mathrm{TiO}_{2}$ crystallites (JCPDS file number 21-1272) [30]. Similarly, ATC aerogels also exhibited typical strong peaks assigned to anatase phase as well as cellulose characteristic peaks at $11.9^{\circ}, 19.8^{\circ}$, and $22.0^{\circ}$ 


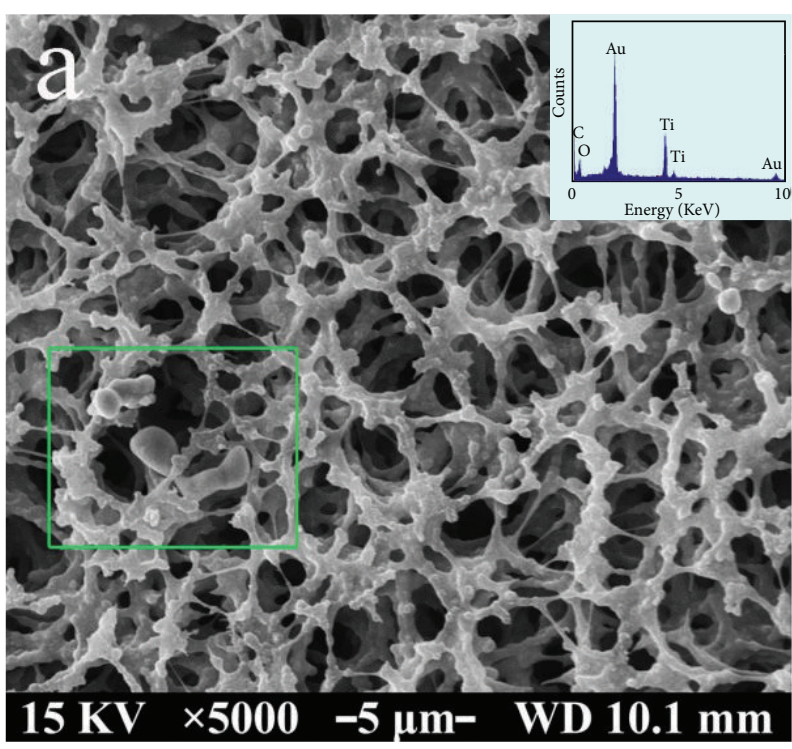

(a)

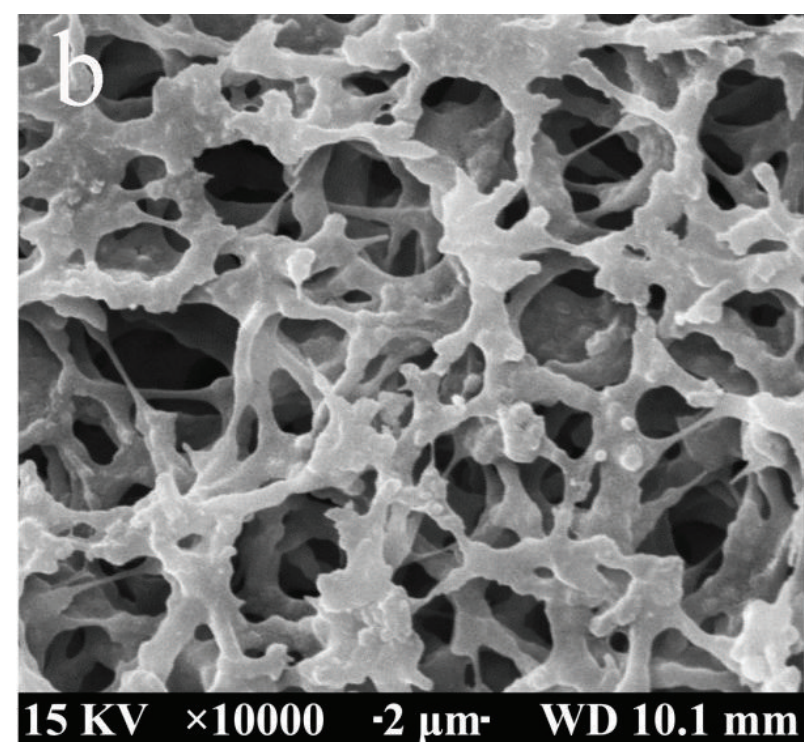

(b)

FIGURE 1: (a) Low-magnification and (b) high-magnification SEM images of ATC aerogels, respectively. The green box was the area of EDX analysis, and the corresponding EDX spectrum was shown in Figure 1 as an inset.

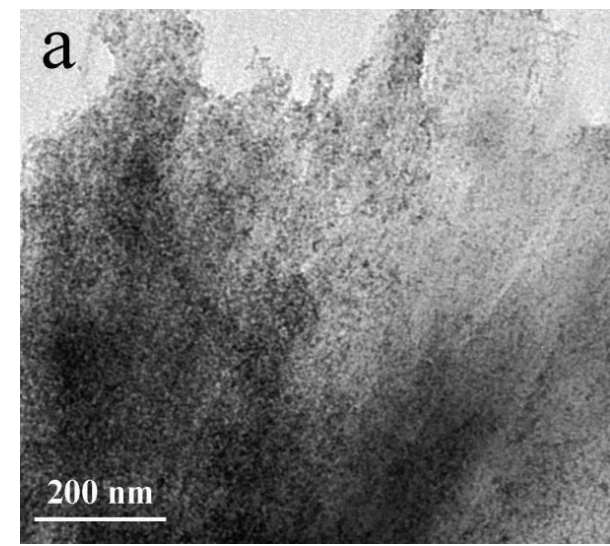

(a)

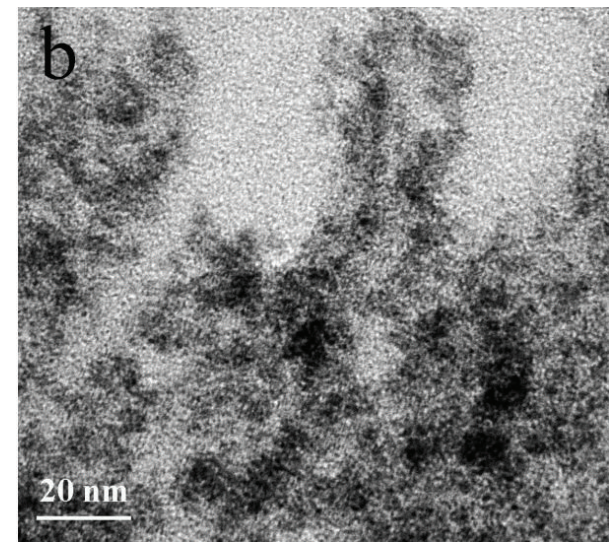

(b)

FIGURE 2: TEM images of different magnifications of ATC aerogels, respectively.

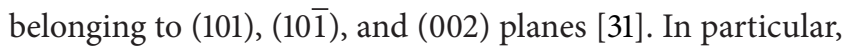
no peaks of rutile $\mathrm{TiO}_{2}$ phase (JCPDS file number 21-1276) were detected, indicating the high anatase phase purity of ATC aerogels. Meanwhile, the result also revealed that the anatase $\mathrm{TiO}_{2}$ was successfully fabricated and combined with cellulose aerogels by the facile low-temperature hydrothermal method. Moreover, it was obvious that the characteristic peaks of the anatase $\mathrm{TiO}_{2}$ were broad, which was an indication of the small size of the $\mathrm{TiO}_{2}$ particles formed in the ATC aerogels. The crystallite size as calculated by the DebyeScherrer equation [32] was $4.3 \mathrm{~nm}$, which was consistent with the TEM results from Figure 2(b).

Figure 4 showed the TG and DTG curves of ATC aerogels and the pure cellulose aerogels, respectively. The DTG curve for pure cellulose aerogels showed one major exothermic peak at around $362^{\circ} \mathrm{C}$, which represented a typical thermal decomposition behavior of cellulose in an inert atmosphere, as previously reported [33]. In comparison, the maximum loss of weight of ATC aerogels shifted to a temperature of $\sim 323^{\circ} \mathrm{C}, 39^{\circ} \mathrm{C}$ lower than that of the pure cellulose aerogels according to the DTG curves. The potential reasons for the shift might be the catalytic character of $\mathrm{TiO}_{2}[34,35]$, and the loosening of molecular chains in crystalline regions of cellulose as the result of infusion of $\mathrm{TiO}_{2}$ particles [36]. Moreover, ATC aerogels had high residual ash (ca. 44.1\%), far higher than that of the pure cellulose aerogels samples (ca. $8.4 \%$ ), which indicated high loading amount of $\mathrm{TiO}_{2}$ in the hybrid ATC aerogels samples (ca. 35.7\%).

$\mathrm{RhB}$ and $\mathrm{MO}$, the two kinds of common organic pollutants, were employed to evaluate the photocatalytic activities of ATC aerogels. For the sake of comprehending the photocatalytic property, the commercially available $\mathrm{TiO}_{2} \mathrm{P} 25$ 


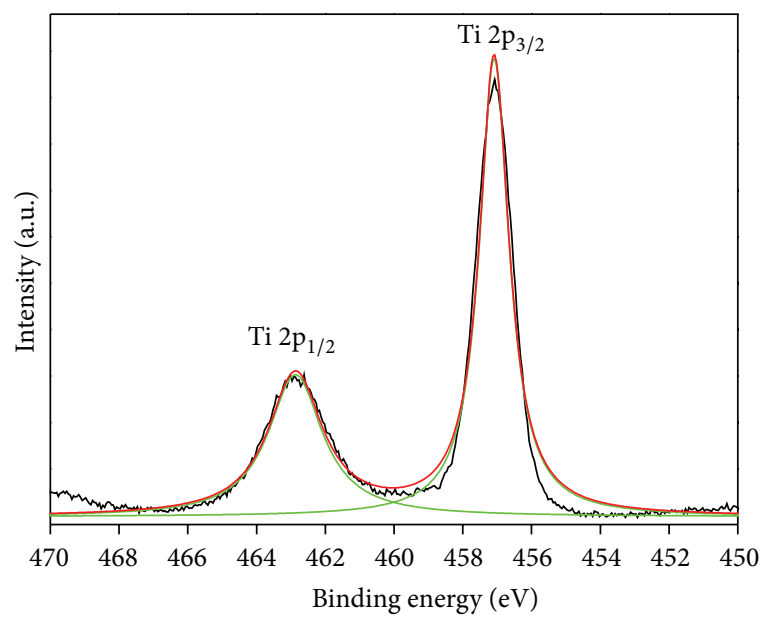

(a)

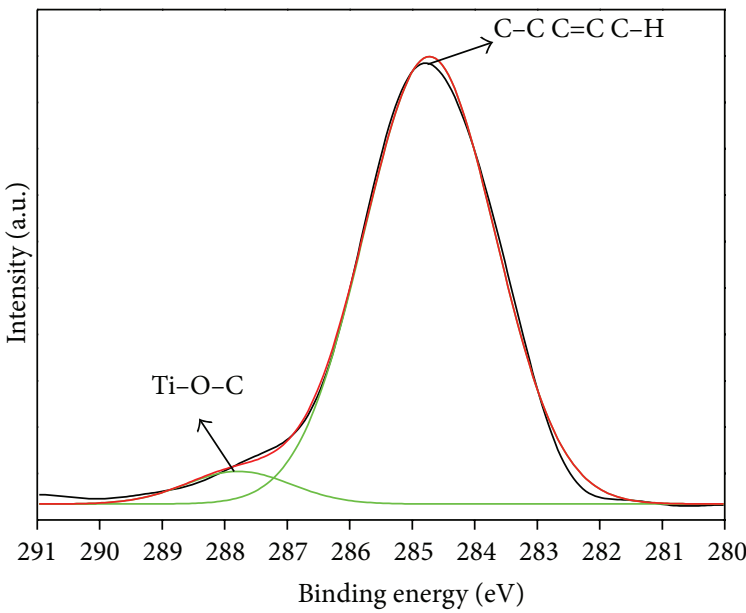

(c)

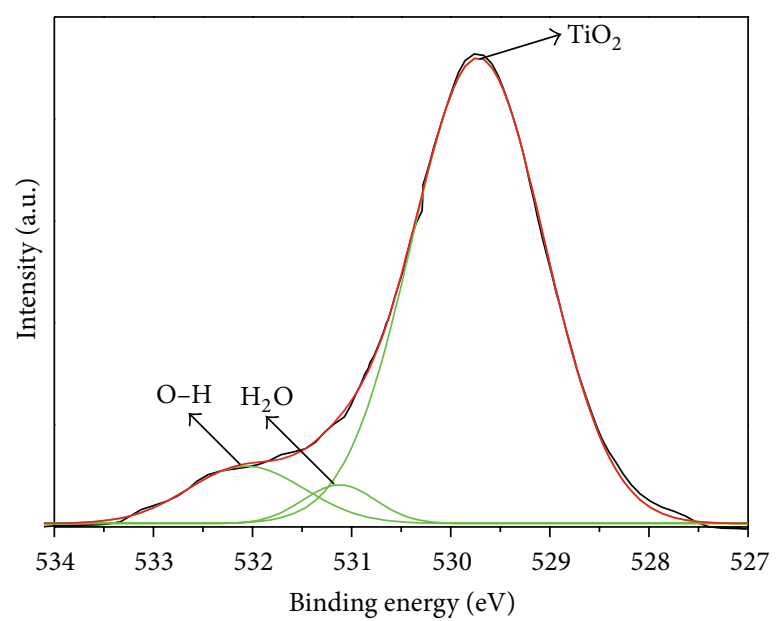

(b)

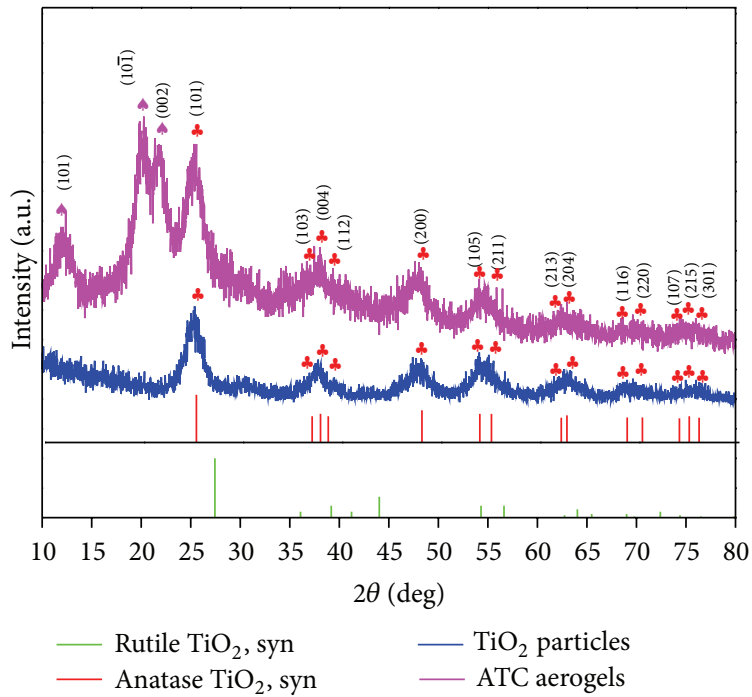

(d)

FIGURE 3: High-resolution XPS spectra of ATC aerogels in (a) Ti 2p, (b) O 1s, and (c) C 1s regions. (d) XRD patterns of the TiO $\mathrm{X}_{2}$ particles and ATC aerogels.

(Degussa, Germany) was used as a photocatalytic reference. As shown in Figure 5(a), the concentrations of the RhB and the MO solutions changed a little for the wheat straw, indicating an inferior photocatalytic performance under UV irradiation. On the contrary, both of P25 and ATC aerogels showed strong photodegradation abilities for $\mathrm{RhB}$ and $\mathrm{MO}$ due to the drastic changes of concentration before and after the experiments. Compared with P25, ATC aerogels exhibited similar concentration change tendency for RhB and slightly faster rate of photocatalytic degradation for $\mathrm{MO}$, respectively, which proved that the photocatalytic activities of ATC aerogels were comparable with those of P25 only taking account of these two kinds of organic pollutants. Moreover, the strong photocatalytic activities of ATC aerogels might be due to good dispersion, potential higher surface area, and smaller crystallite size of the formed anatase $\mathrm{TiO}_{2}[37,38]$. Furthermore, Figure 5(b) showed the macrographs of RhB and MO degradations by ATC aerogels, and the significant color differences before and after the UV radiation further indicated the superior photocatalytic activities of ATC aerogels.

Based on the results mentioned above, photocatalytic reaction behaviors of ATC aerogels under UV irradiation for RhB and MO degradations were illuminated in Figure 6. When the surface of ATC aerogels was illuminated by UV light with energy equal to or larger than the band gap energy of anatase $\mathrm{TiO}_{2}$ nanocrystals, the electrons were excited in the valance band $(\mathrm{VB})$ to the conduction band $(\mathrm{CB})$, leading to the formation of a positive hole $\left(\mathrm{h}^{+}\right)$in the $\mathrm{VB}$ and an electron $\left(\mathrm{e}^{-}\right)$in the CB [39-41]. The generated electronhole pairs immediately interacted with surface adsorbed molecular oxygen to yield superoxide radical anions $\left({ }^{\circ} \mathrm{O}_{2}{ }^{-}\right)$ and with water to produce the highly reactive $\mathrm{HO}^{\bullet}$ radicals, respectively. These radicals groups repeatedly attacked $\mathrm{RhB}$ and MO molecules, eventually resulting in their degradations 


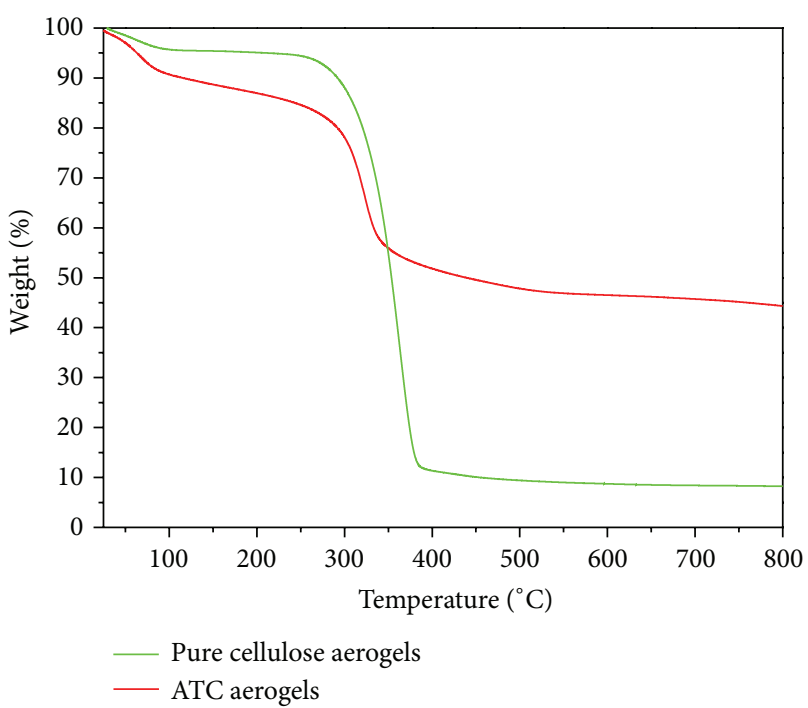

(a)

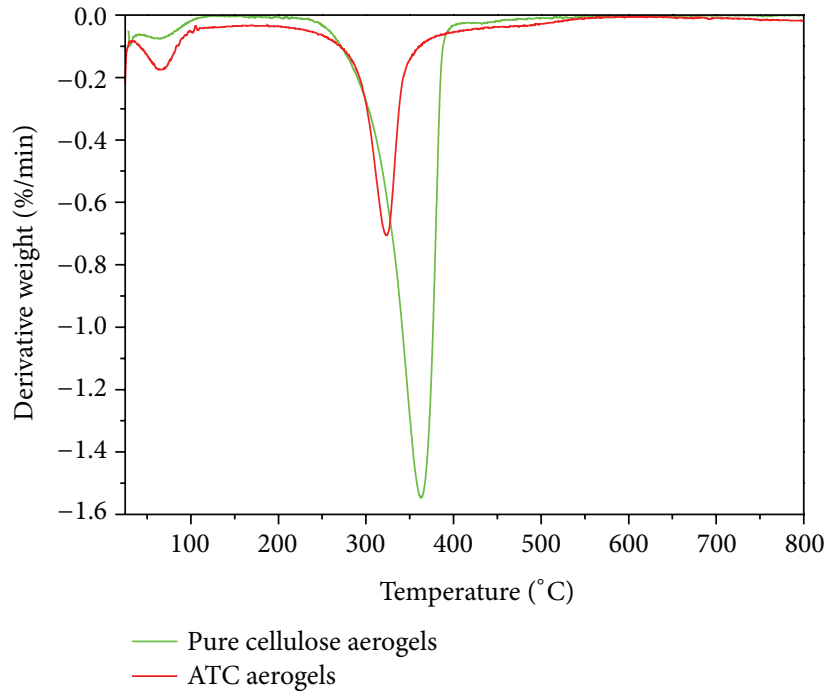

(b)

FIGURE 4: TG and DTG curves of ATC aerogels and the pure cellulose aerogels, respectively.
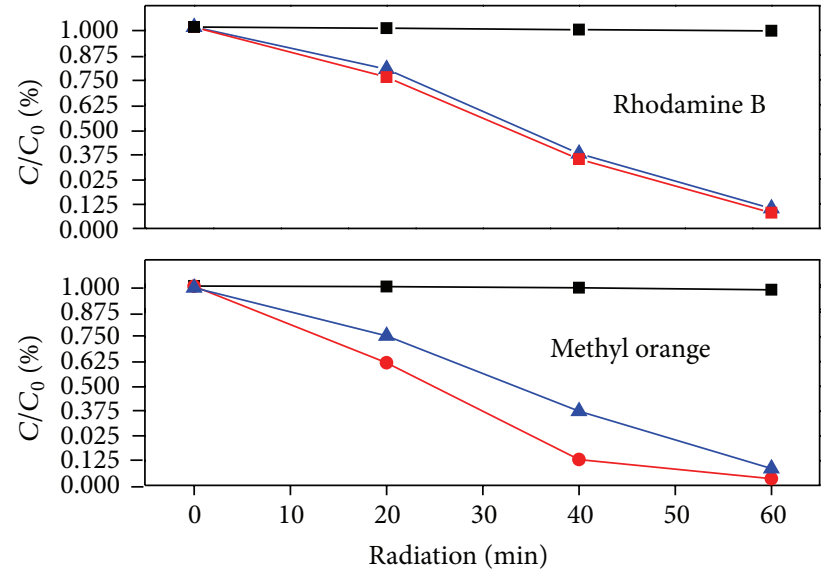

Wheat straw
P25
_ ATC aerogels

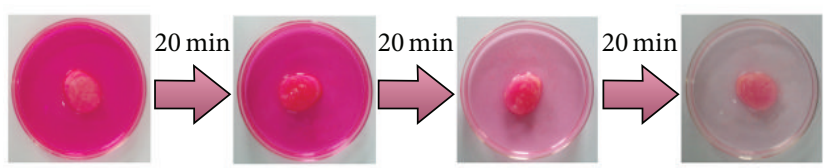

Rhodamine B

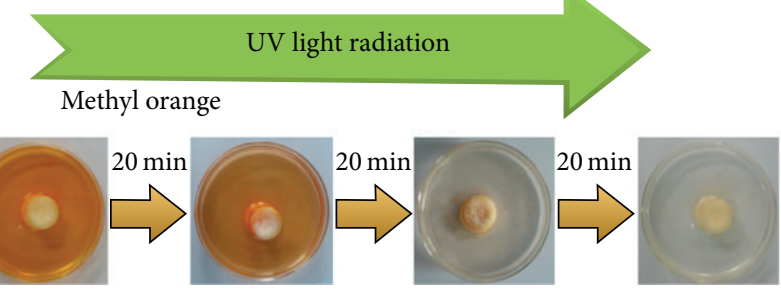

(b)

FIgURE 5: (a) Photocatalytic activities of the wheat straw, P25, and ATC aerogels for RhB and MO degradations. (b) Macrographs of RhB and MO degradations by ATC aerogels under UV radiation.

into $\mathrm{CO}_{2}$ and $\mathrm{H}_{2} \mathrm{O}[42,43]$, which were responsible for the photocatalytic activity.

\section{Conclusions}

In conclusion, ATC aerogels were successfully fabricated via a mild simple low-temperature hydrothermal method. The as-prepared ATC aerogels were composed of cross-linked 3D architecture originated from the original cellulose hydrogels, and the 3D architecture was surrounded by plentiful ellipsoidal aggregations formed by a mass of evenly dispersed anatase $\mathrm{TiO}_{2}$ nanoparticles with sizes of 2-5 nm. Meanwhile, a high loading amount of $\mathrm{TiO}_{2}$ in the hybrid ATC aerogels samples (ca. 35.7\%) was also obtained according to the TG results. Moreover, the ATC aerogels exhibited comparable photocatalytic activities for RhB and MO degradations with Degussa P25 under UV radiation, which might be served as novel green catalysts for water decontamination and organic pollutants decomposition.

\section{Conflict of Interests}

The authors declare that there is no conflict of interests regarding the publication of this paper. 


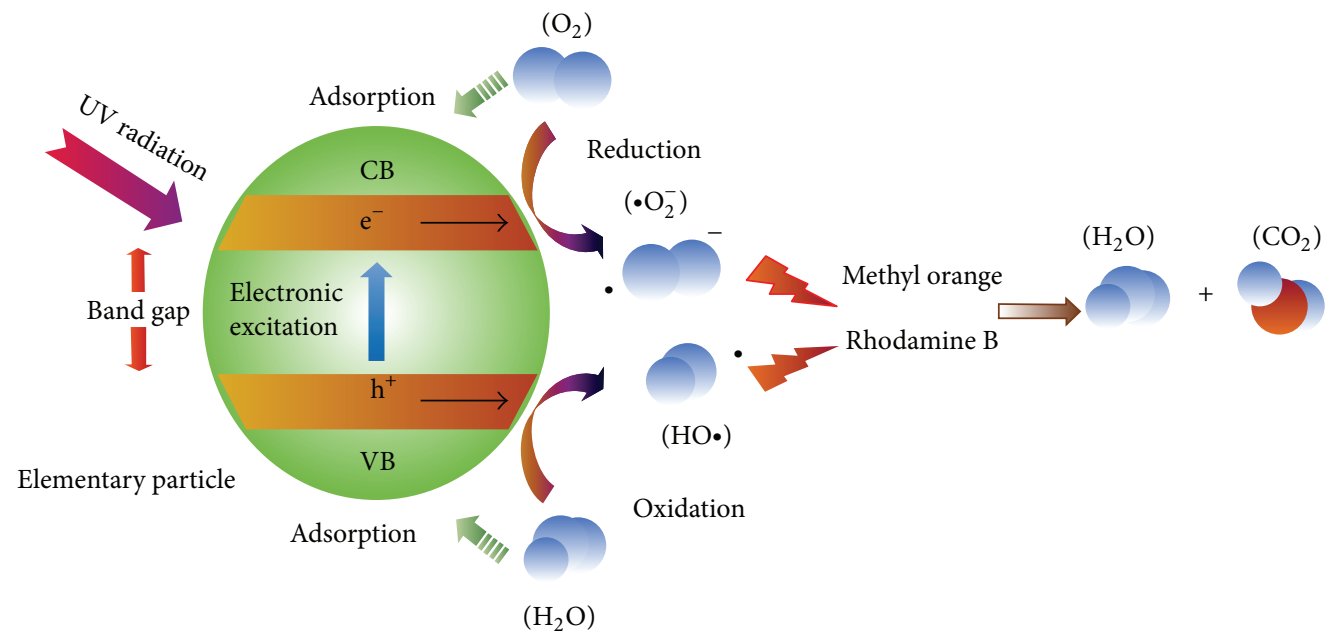

FIGURE 6: Schematic representation of the photocatalytic mechanism of ATC aerogels.

\section{Acknowledgments}

The authors appreciate the financial support of the China Postdoctoral Science Foundation (2013M540263), the National Natural Science Foundation of China (Grant no. 31270590), and the Doctoral Candidate Innovation Research Support Program of Science \& Technology Review (kjdb2012006).

\section{References}

[1] X. Chen and S. S. Mao, "Titanium dioxide nanomaterials: synthesis, properties, modifications and applications," Chemical Reviews, vol. 107, no. 7, pp. 2891-2959, 2007.

[2] S. Gelover, P. Mondragón, and A. Jiménez, “Titanium dioxide sol-gel deposited over glass and its application as a photocatalyst for water decontamination," Journal of Photochemistry and Photobiology A: Chemistry, vol. 165, no. 1-3, pp. 241-246, 2004.

[3] R. L. Pozzo, M. A. Baltanás, and A. E. Cassano, "Supported titanium oxide as photocatalyst in water decontamination: state of the art," Catalysis Today, vol. 39, no. 3, pp. 219-231, 1997.

[4] Q. Sun, Y. Lu, H. Zhang et al., "Hydrothermal fabrication of rutile $\mathrm{TiO}_{2}$ submicrospheres on wood surface: an efficient method to prepare UV-protective wood," Materials Chemistry and Physics, vol. 133, no. 1, pp. 253-258, 2012.

[5] J. Sun, L. Gao, and Q. Zhang, "Synthesizing and comparing the photocatalytic properties of high surface area rutile and anatase titania nanoparticles," Journal of the American Ceramic Society, vol. 86, no. 10, pp. 1677-1682, 2003.

[6] D. C. Hurum, A. G. Agrios, K. A. Gray, T. Rajh, and M. C. Thurnauer, "Explaining the enhanced photocatalytic activity of Degussa P25 mixed-phase $\mathrm{TiO}_{2}$ using EPR," The Journal of Physical Chemistry B, vol. 107, no. 19, pp. 4545-4549, 2003.

[7] X.-H. Xia, Z.-J. Jia, Y. Yu, Y. Liang, Z. Wang, and L.-L. Ma, "Preparation of multi-walled carbon nanotube supported $\mathrm{TiO}_{2}$ and its photocatalytic activity in the reduction of $\mathrm{CO}_{2}$ with $\mathrm{H}_{2} \mathrm{O}$," Carbon, vol. 45, no. 4, pp. 717-721, 2007.

[8] Y. Yu, J. C. Yu, C.-Y. Chan et al., "Enhancement of adsorption and photocatalytic activity of $\mathrm{TiO}_{2}$ by using carbon nanotubes for the treatment of azo dye," Applied Catalysis B: Environmental, vol. 61, no. 1-2, pp. 1-11, 2005.
[9] Y. Yu, J. C. Yu, J.-G. Yu et al., "Enhancement of photocatalytic activity of mesoporous $\mathrm{TiO}_{2}$ by using carbon nanotubes," Applied Catalysis A: General, vol. 289, no. 2, pp. 186-196, 2005.

[10] Z.-S. Wu, W. Ren, L. Wen et al., "Graphene anchored with $\mathrm{Co}_{3} \mathrm{O}_{4}$ nanoparticles as anode of lithium ion batteries with enhanced reversible capacity and cyclic performance," ACS Nano, vol. 4, no. 6, pp. 3187-3194, 2010.

[11] X. Zheng, D. Guo, Y. Shao et al., "Photochemical modification of an optical fiber tip with a silver nanoparticle film: a SERS chemical sensor," Langmuir, vol. 24, no. 8, pp. 4394-4398, 2008.

[12] J. M. Miller, B. Dunn, T. D. Tran, and R. W. Pekala, "Deposition of ruthenium nanoparticles on carbon aerogels for high energy density supercapacitor electrodes," Journal of the Electrochemical Society, vol. 144, no. 12, pp. L309-L311, 1997.

[13] C. D. Saquing, D. Kang, M. Aindow, and C. Erkey, "Investigation of the supercritical deposition of platinum nanoparticles into carbon aerogels," Microporous and Mesoporous Materials, vol. 80, no. 1, pp. 11-23, 2005.

[14] J. Cai, S. Kimura, M. Wada, and S. Kuga, "Nanoporous cellulose as metal nanoparticles support," Biomacromolecules, vol. 10, no. 1, pp. 87-94, 2009.

[15] R. J. Moon, A. Martini, J. Nairn, J. Simonsen, and J. Youngblood, "Cellulose nanomaterials review: structure, properties and nanocomposites," Chemical Society Reviews, vol. 40, no. 7, pp. 3941-3994, 2011.

[16] P. Tingaut, T. Zimmermann, and G. Sèbe, "Cellulose nanocrystals and microfibrillated cellulose as building blocks for the design of hierarchical functional materials," Journal of Materials Chemistry, vol. 22, no. 38, pp. 20105-20111, 2012.

[17] N. D. Luong, Y. Lee, and J.-D. Nam, "Highly-loaded silver nanoparticles in ultrafine cellulose acetate nanofibrillar aerogel," European Polymer Journal, vol. 44, no. 10, pp. 3116-3121, 2008.

[18] Y. Lu, Q. Sun, J. Li, and Y. Liu, "Fabrication, characterization and photocatalytic activity of $\mathrm{TiO}_{2}$ /cellulose composite aerogel," Key Engineering Materials, vol. 609-610, pp. 542-546, 2014.

[19] T. W. Hamann, A. B. F. Martinson, J. W. Elam, M. J. Pellin, and J. T. Hupp, "Atomic layer deposition of $\mathrm{TiO}_{2}$ on aerogel templates: new photoanodes for dye-sensitized solar cells," The Journal of Physical Chemistry C, vol. 112, no. 27, pp. 10303-10307, 2008. 
[20] M. Kusabe, H. Kozuka, S. Abe, and H. Suzuki, "Sol-gel preparation and properties of hydroxypropylcellulose-titania hybrid thin films," Journal of Sol-Gel Science and Technology, vol. 44, no. 2, pp. 111-118, 2007.

[21] H. Shin, D.-K. Jeong, J. Lee, M. M. Sung, and J. Kim, "Formation of $\mathrm{TiO}_{2}$ and $\mathrm{ZrO}_{2}$ nanotubes using atomic layer deposition with ultraprecise control of the wall thickness," Advanced Materials, vol. 16, no. 14, pp. 1197-1200, 2004.

[22] L. Melone, L. Altomare, I. Alfieri, A. Lorenzi, L. de Nardo, and C. Punta, "Ceramic aerogels from TEMPO-oxidized cellulose nanofibre templates: synthesis, characterization, and photocatalytic properties," Journal of Photochemistry and Photobiology A: Chemistry, vol. 261, pp. 53-60, 2013.

[23] N. S. Venkataramanan, K. Matsui, H. Kawanami, and Y. Ikushima, "Green synthesis of titania nanowire composites on natural cellulose fibers," Green Chemistry, vol. 9, no. 1, pp. 18-19, 2007.

[24] K. Nelson and Y. Deng, "Enhanced light scattering from hollow polycrystalline $\mathrm{TiO}_{2}$ particles in a cellulose matrix," Langmuir, vol. 24, no. 3, pp. 975-982, 2008.

[25] J. Li, C. C. Wan, Y. Lu, and Q. F. Sun, "Fabrication of cellulose aerogel from wheat straw with strong absorptive capacity," Frontiers of Agricultural Science and Engineering, vol. 1, no. 1, pp. 46-52, 2014.

[26] B. Wang, R. Karthikeyan, X.-Y. Lu, J. Xuan, and M. K. Leung, "High photocatalytic activity of immobilized $\mathrm{TiO}_{2}$ nanorods on carbonized cotton fibers," Journal of Hazardous Materials, vol. 263, part 2, pp. 659-669, 2013.

[27] B. Erdem, R. A. Hunsicker, G. W. Simmons, E. David Sudol, V. L. Dimonie, and M. S. El-Aasser, "XPS and FTIR surface characterization of $\mathrm{TiO}_{2}$ particles used in polymer encapsulation," Langmuir, vol. 17, no. 9, pp. 2664-2669, 2001.

[28] C. Hu, S. Duo, T. Liu, W. Li, and R. Zhang, "Low temperature facile synthesis of anatase $\mathrm{TiO}_{2}$ coated multiwalled carbon nanotube nanocomposites," Materials Letters, vol. 64, no. 22, pp. 2472-2474, 2010.

[29] W.-J. Gong, H.-W. Tao, G.-L. Zi et al., "Visible light photodegradation of dyes over mesoporous titania prepared by using chrome azurol S as template," Research on Chemical Intermediates, vol. 35, no. 6-7, pp. 751-760, 2009.

[30] J. Ye, W. Liu, J. Cai et al., "Nanoporous anatase $\mathrm{TiO}_{2}$ mesocrystals: additive-free synthesis, remarkable crystalline-phase stability, and improved lithium insertion behavior," Journal of the American Chemical Society, vol. 133, no. 4, pp. 933-940, 2011.

[31] P. Mansikkamäki, M. Lahtinen, and K. Rissanen, "Structural changes of cellulose crystallites induced by mercerisation in different solvent systems; determined by powder X-ray diffraction method," Cellulose, vol. 12, no. 3, pp. 233-242, 2005.

[32] T. J. Trentler, T. E. Denler, J. F. Bertone, A. Agrawal, and V. L. Colvin, "Synthesis of $\mathrm{TiO}_{2}$ nanocrystals by nonhydrolytic solution-based reactions," Journal of the American Chemical Society, vol. 121, no. 7, pp. 1613-1614, 1999.

[33] F. Shafizadeh and A. Bradbury, "Thermal degradation of cellulose in air and nitrogen at low temperatures," Journal of Applied Polymer Science, vol. 23, no. 5, pp. 1431-1442, 1979.

[34] D. C. Schnitzler and A. J. Zarbin, "Organic/inorganic hybrid materials formed from $\mathrm{TiO}_{2}$ nanoparticles and polyaniline," Journal of the Brazilian Chemical Society, vol. 15, no. 3, pp. 378384, 2004.
[35] H. Wang, W. Zhong, P. Xu, and Q. Du, "Polyimide/silica/titania nanohybrids via a novel non-hydrolytic sol-gel route," Composites Part A: Applied Science and Manufacturing, vol. 36, no. 7, pp. 909-914, 2005.

[36] Q. Yu, P. Wu, P. Xu, L. Li, T. Liu, and L. Zhao, "Synthesis of cellulose/titanium dioxide hybrids in supercritical carbon dioxide," Green Chemistry, vol. 10, no. 10, pp. 1061-1067, 2008.

[37] D. Sun, J. Yang, and X. Wang, "Bacterial cellulose/ $\mathrm{TiO}_{2}$ hybrid nanofibers prepared by the surface hydrolysis method with molecular precision," Nanoscale, vol. 2, no. 2, pp. 287-292, 2010.

[38] W.-L. Guo, Z.-X. Yang, and X.-K. Wang, "Sonochemical deposition and characterization of nanophasic $\mathrm{TiO}_{2}$ on silica particles," Materials Research Innovations, vol. 10, no. 1, pp. 11-13, 2006.

[39] I. Moon, S. Vigneswaran, and R. Thiruvenkatachari, "A review on $\mathrm{UV} / \mathrm{TiO}_{2}$ photocatalytic oxidation process," 2008.

[40] N. A. Laoufi, D. Tassalit, and F. Bentahar, "The degradation of phenol in water solution by $\mathrm{TiO}_{2}$ photocatalysis in a helical reactor," Global Nest Journal, vol. 10, no. 3, pp. 404-418, 2008.

[41] U. Sirimahachai, N. Ndiege, R. Chandrasekharan, S. Wongnawa, and M. A. Shannon, "Nanosized $\mathrm{TiO}_{2}$ particles decorated on $\mathrm{SiO}_{2}$ spheres $\left(\mathrm{TiO}_{2} / \mathrm{SiO}_{2}\right)$ : synthesis and photocatalytic activities," Journal of Sol-Gel Science and Technology, vol. 56, no. 1, pp. 53-60, 2010.

[42] M. Rani, N. Gupta, and B. Pal, "Superior photodecomposition of pyrene by metal ion-loaded $\mathrm{TiO}_{2}$ catalyst under UV light irradiation," Environmental Science and Pollution Research, vol. 19, no. 6, pp. 2305-2312, 2012.

[43] M. Rǎileanu, M. Crişan, I. Niţoi et al., " $\mathrm{TiO}_{2}$-based nanomaterials with photocatalytic properties for the advanced degradation of xenobiotic compounds from water. A literature survey," Water, Air, and Soil Pollution, vol. 224, no. 6, article 1548, 2013. 

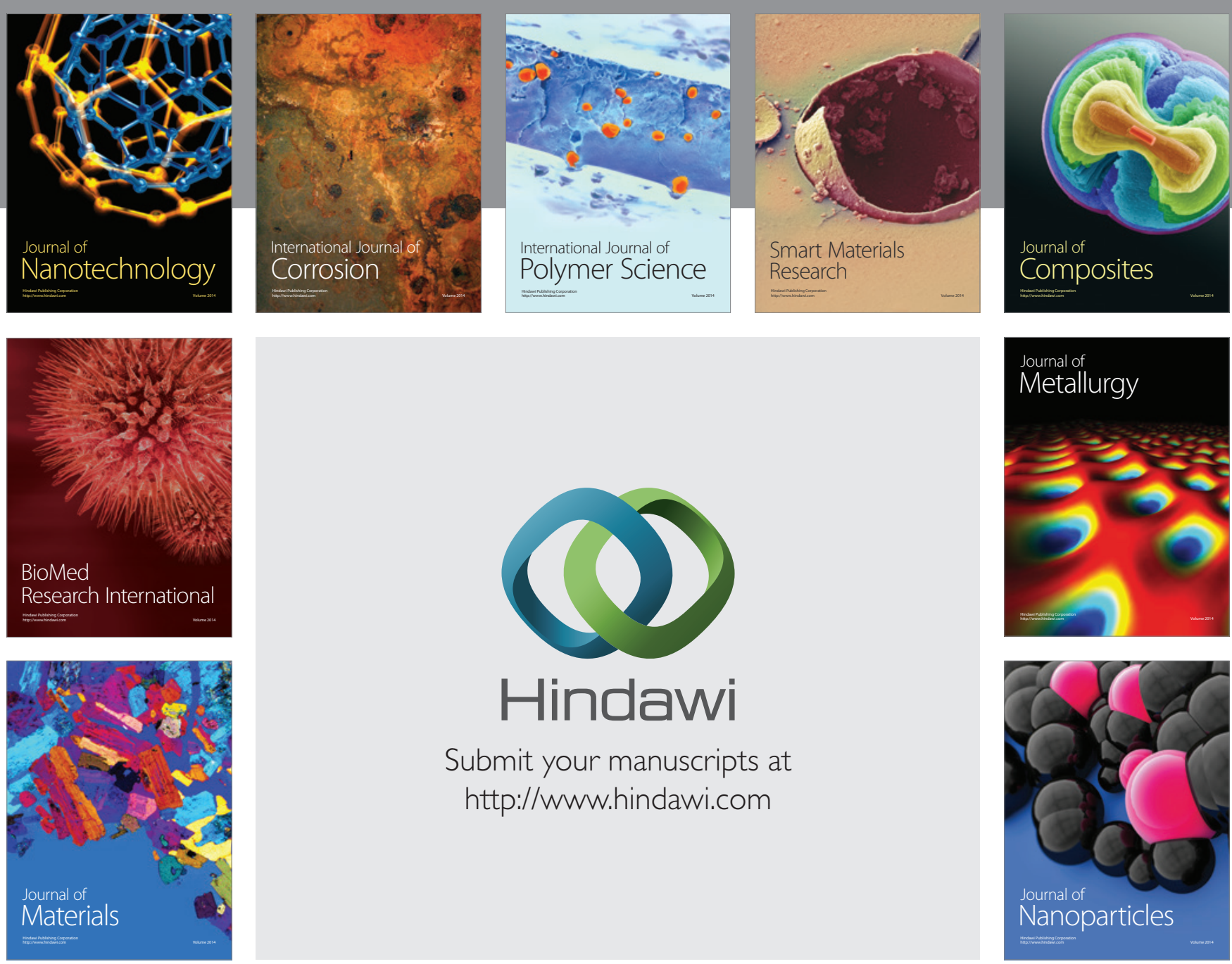

Submit your manuscripts at http://www.hindawi.com
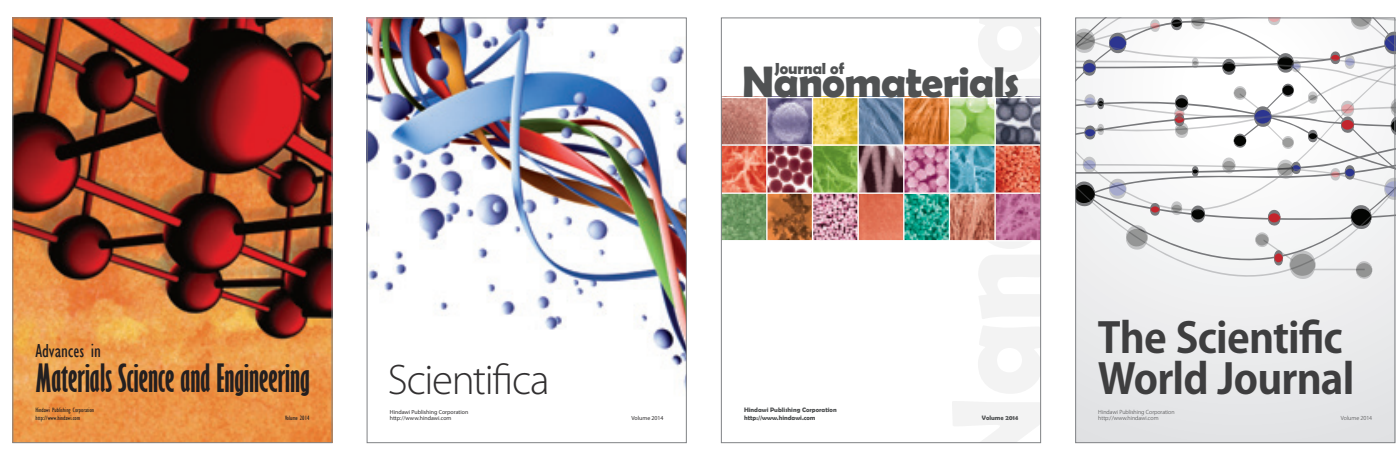

\section{The Scientific World Journal}
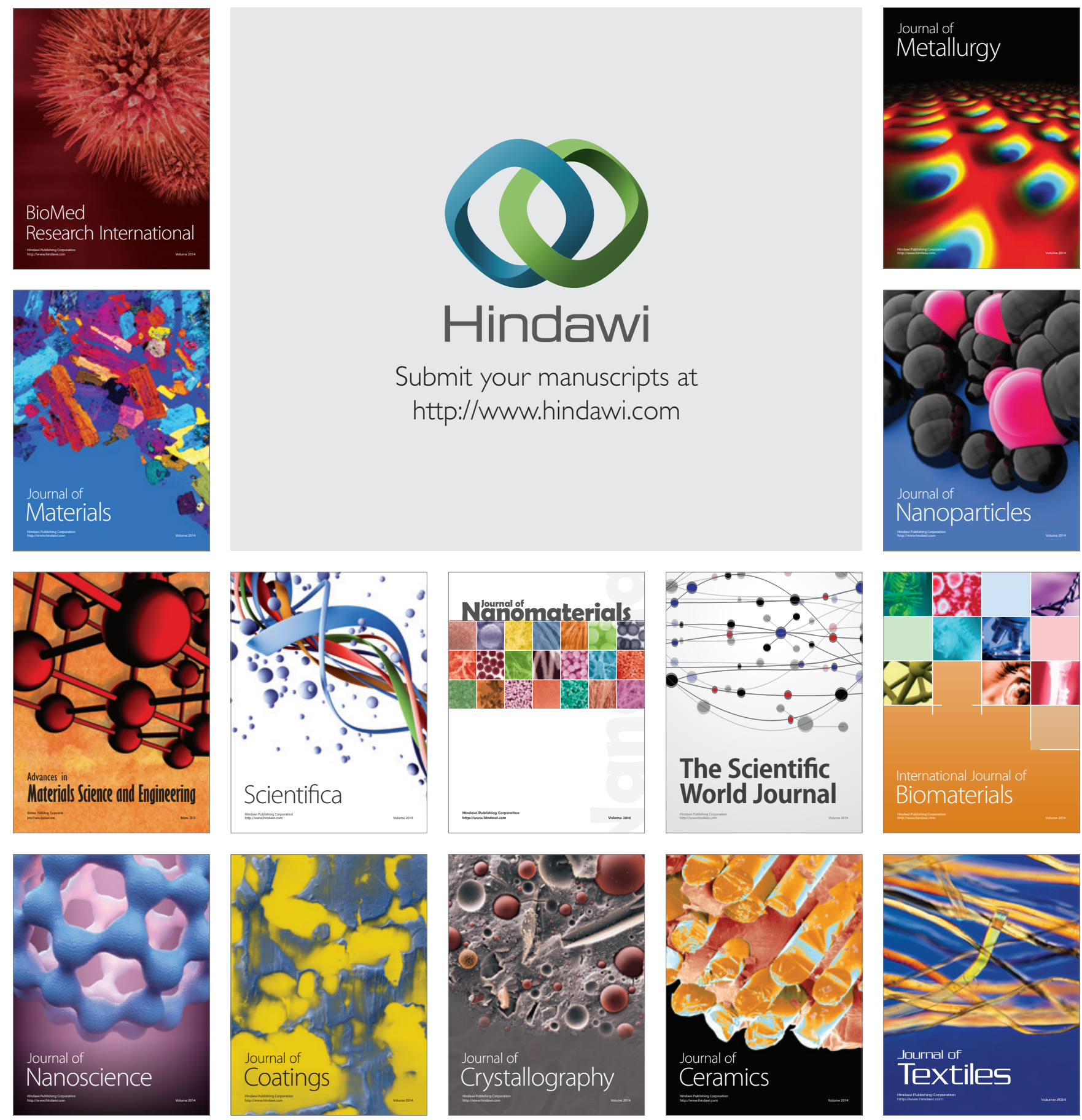